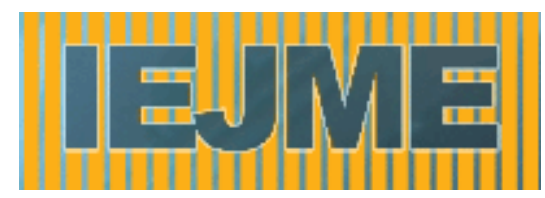

\author{
International Electronic Journal of
}

\title{
Mathematics Education
}

\section{DO YOU WANT ME TO DO IT WITH PROBABILITY OR \\ WITH MY NORMAL THINKING? - HORIZONTAL AND VERTICAL VIEWS \\ ON THE FORMATION OF STOCHASTIC CONCEPTIONS}

Susanne Prediger

\begin{abstract}
Probability classrooms often fail to develop sustainable conceptions of probability as strategic tools that can be activated for decisions in everyday random situations. The article starts from the assumption that one important reason might be the often empirically reconstructed divergence between individual conceptions of probabilistic phenomena and the normative conceptions taught in probability classrooms, especially concerning pattern in random. Since the process of dealing with these phenomena cannot sufficiently be explained by existing frameworks alone, an alternative - horizontal - view on conceptual change is proposed. Its use for research and development within the so-called Educational Reconstruction Program is presented. The empirical part of the paper is based on a qualitative study with 10 game interviews. Central results concern the oszillation between conceptions and cognitive layers and the situatedness of their activation. In particular, diverging perspectives seem to root in contrasting foci of attention, namely the mathematically suitable long-term perspective being in concurrence to the more natural short-term attention to single outcomes. The Educational Reconstruction Program offers an interesting possibility to specify roots of obstacles and to develop guidelines for designing learning environments which respect the horizontal view.
\end{abstract}

KEYWORDS. Probability, Random, Student Conceptions, Conceptual Change, Horizontal View.

\section{INTRODUCTION}

\section{The problem}

"Do you want me to do it with probability or with my normal thinking?"

This question, posed by Anne, an eleven-year old student in the author`s probability class, was one important starting point for the individual research interest underlying this article. While solving probability tasks, Anne perceived a strong gap between the conceptions demanded 
in probability classrooms and her individual conceptions. This article is based on the assumption that this (felt) gap is one (not the only) major reason for limited success of many probability classrooms.

Limited success has been attested to probability classrooms by many researchers who found eminent learning difficulties and persistent misconceptions in their empirical studies (Kahneman \& Tversky, 1982 or Fischbein et al., 1991, for two of the most prominent examples). The large body of insightful research literature on misconceptions and difficulties has often been resumed andneed not be reviewed here again (see the good surveys Shaughnessy, 1992; Borovcnik \& Peard, 1996, Watson, 2005).

An even more striking instance of limited success of probability classrooms is the phenomenon that people who mastered probability successfully in school often refuse to use it in their everyday life like in playing situations. This phenomenon has been described, for example, by Shaughnessy:

"What fascinates me [...] was that the subjects in those studies could have used elementary probability and statistics concepts to estimate the likelihood of events in the research tasks that were given, but they didn't." (Shaughnessy, 1992, p. 465, italics in original)

In his example, Shaughnessy describes prototypical persons for which the probability classroom failed to anchor the concept of probability in their individual thinking as a strategic tool that is activated for decisions in random situations out-of-school.

This phenomenon is disconcerting since these persons could not achieve a central aim of mathematical literacy, namely to acquire mathematical concepts, structures and ideas "as tools to organise the phenomena of the physical, social and mental world" (Freudenthal, 1983, p. IX). Especially crucial are those situations which do not demand the transition of difficult stochastic paradoxes but only elementary stochastic thinking (cf. Prediger, 2005). What exactly are the obstacles for more successful transitions?

Although there is much research on stochastic (mis)conceptions concerning very different phenomena (see above), most of the empirical studies and articles presuppose that the people under consideration do activate stochastic thinking, i.e. that they use their individual probabilistic concepts (although these are perhaps diverging from the mathematical ones).

The focus of this article is more fundamental in the sense that it considers the general willingness to activate stochastic thinking in out-of school contexts at all. This disposition for 
transition is a basic, necessary (but of course not sufficient) condition for successful stochastic thinking.

\section{Research Questions and Structure}

The central question guiding to the author's design research in a long-term perspective is

(1) How should learning arrangements be designed for that the concept of probability is activated as a strategic tool for decisions in random situations?

It is treated in a long-term project and started step by step along the following questions:

(2) How can the (perceived) gap between everyday conceptions and mathematical conceptions be conceptualized theoretically so that it can offer an orientation for the design aimed at in question (1)?

(3) What are main differences between everyday and mathematical conceptions for the specific subject probability that feed the perception of a gap?

(4) How can the individual repertoire of prior conceptions be extended to mathematical conceptions, and how can learners be enabled to chose the adequate conceptions in varying contexts?

(5) How can we build bridges between individual and mathematical conceptions?

(6) In which research framework can the empirical studies concerning question (3) be combined most successfully with design considerations of question (5)?

The article takes the risk of not adopting the usual style of a classical research report that documents design and results of one finished research study in a systematic way. Instead, it intends to report on a longer-term process with different steps of theory building, mathematics considerations and selected results from three small-scale qualitative empirical studies (of which only one can be presented in more depth). The article presents longer-term research as an (ongoing) process, in analogy to the process-orientation demanded from reform mathematics classrooms.

The research process starts with making explicit an adequate conceptualization of the learning processes in order to substantiate the assumption that the transition problem is linked to the differences between everyday and mathematical conceptions (Section 2). The suggested horizontal view on the formation of conceptions has a critical normative part that must be explained in Section 2.3. 
In the next step, a long-term research program is presented that is suitable for this purposes insofar as it puts these differences into the centre, namely the Educational Reconstruction Program (Duit et al., 2005). Its basic theories and methodological components have proved to be very fruitable when a mediation between individual and scientific conceptions is needed.

The program does not only intend to analyse and understand learning difficulties but also to develop learning environments for overcoming difficulties and for initiating more sustainable learning processes as will be outlined in Section 3. Section 4 shows how the program was applied to the one special case of elementary use of stochastic conceptions.

\section{THEORETICAL BACKGROUND:}

\section{VERTICAL AND HORIZONTAL VIEWS ON THE FORMATION OF CONCEPTIONS}

Why do probability classes often fail to install the concept of probability as a strategic tool that is activated for decisions in random situations, even if the concepts are successfully learned in school? Before giving a theoretical account for this transition problem, it is important to remark, that it is not specific to probability but a well-known and largely discussed problem in mathematics and science education. Especially science education studies have often described the problem that students successfully acquire scientific conceptions in the classroom, whereas in out-of-school situations, they prefer relying on their pre-instructional everyday conceptions (Duit et al., 2005).

The term 'conception' itself must be explained since it is widely used in mathematics education but with very different meanings (cf. Kaldrimidou \& Tzekaki, 2006 for a critical overview on different uses). In this article, conceptions are defined as all cognitive constructs which "students use in order to interpret their experience" (Kattmann \& Gropengießer, 1996, p. 182). These constructs are located on different epistemological levels of complexity, comprising for example concepts, intuitive rules, thinking forms, and local theories (Gropengießer, 2001, pp. $30 \mathrm{ff}$.).

\section{Social Constructivism as a Background}

The article is based on a social constructivist position (e.g. Ernest, 1994), in which the generation of sustainable mathematical conceptions is conceptualized as an active, individual construction of mental structures. Hence, the formation process of conceptions cannot be 
understood in simple terms of cause and effect relations between instruction and learning (cf. e.g. Knuth \& Cunningham, 1993; Gerstenmaier \& Mandl, 1995). Constructivist epistemology starts from the basic assumption that each perceptive activity of an individual consists of construction and interpretation, being regulated by social negotiation and the need to fit to the experienced phenomena (Ernest, 1994, p. 330 ff).

This offers a first account for the empirically manifest phenomenon that not all learning processes happen as intended by the teachers, since the internal processes of construction can only be influenced indirectly. Nevertheless, this does not presuppose teaching to have no impact on individual learning processes. Instead, it is supposed that learning trajectories can be initiated and influenced by designing appropriate learning environments (Sierpinska \& Lerman, 1996 for an overview).

Beyond designing principles for learning environments, the social constructivist basis offers the emphasis on the importance of pre-instructional conceptions as a central influencing factor for formation processes of conceptions.

\section{Prior Conceptions and Conceptual Change in a Vertical View}

Whereas some researchers focus on the dissonance between everyday conceptions and scientific conceptions, this article prefers the wider notion prior conceptions, meaning conceptions that individuals have constructed before a systematic instruction on the specific subject. These can be everyday conceptions but also those acquired earlier in the school biography (which is important for example in the context of extending number domains; Prediger, 2008).

Empirical studies in science education research have shown that the persistency of preinstructional conceptions is one of the key reasons for the instability of scientific conceptions in the individual thinking.

"Learning processes proved to be most crucially influenced by the pre-instructional conceptions that student bring with them into the classrooms ... These conceptions determine how aspects presented by the teacher or the textbook are interpreted and hence how they are understood. Often, the pre-instructional conceptions and the conceptions to be learned are contradictory to each other. This is our account for many learning difficulties which lead, in the sum, to an only poor success of many scientific classrooms." (Duit \& von Rhöneck, 1996, p.7, translated SP). 
Although prior conceptions had seldom been considered in mathematics education in many domains, research in probability learning has already been concerned with it since the 1970ies. One starting point were Fischbein's studies on primary intuitions (1975); Shaughnessy (1992) called their existence a "major problem for the teaching and learning of probability and statistics concepts" (p. 472) and summarizes:

"Our students are not tabulae rasae, waiting for the normative theory of probability to descend from our lips. Students already have their own built-in heuristics, biases, and beliefs about probability and statistics.” (Shaughnessy, 1992, p. 472, see also Konold, 1989)

With respect to the importance of everyday conceptions, probability seems to play a special role within the mathematical domains. Due to their abstractness, many mathematical objects seem to be less connected to the everyday thinking than in science education. In contrast, probabilistic concepts describe empirical phenomena of randomness which play a similar role in everyday life as for scientific concepts.

On the theoretical level, the importance of individual prior conceptions in all domains can be explained on the basis of the constructivist position: individual, active constructions of mental structures always build upon the existing prior mental structures by appropriation to experiences with new phenomena (Gerstenmaier \& Mandl, 1995).

The general constructivist account for the crucial role of prior conceptions has been extended to the so-called conceptual change approach (Posner et al., 1982; Duit \& Treagust, 2003). According to the conceptual change approach, learning mostly means "re-learning, since prior conceptions and scientific conceptions are often opposed to each other in central aspects" (Duit \& von Rhöneck, 1996, p.158, translation SP) .

Although the conceptual change approach has gained growing interest in mathematical areas like arithmetic (e.g. Vosniadou \& Verschaffel, 2004, Prediger, 2008), it has seldom been applied to probability. One important exception is Konold (1991), who used the conceptual change approach in order to describe students' difficulties and possible strategies to facilitate conceptual change in probability:

"Long before their formal introduction to probability, students have dealt with countless situations involving uncertainty and have learned to use words such as probable, random, independent, lucky, chance, fair, unlikely. ... It is into this web of meanings that students attempt to integrate and thus to make sense of their classroom experience... My assumption is that students have intuitions about probability, and that they can't check these in at the classroom 
door. The success of the teacher depends on how these notions are treated in relation to those the teacher would like the students to acquire..." (Konold, 1991, p. 144)

In consequence, Konold suggests several instructional techniques for confronting and overcoming stochastic misconceptions developed by physics educators for dealing with students' pre-instructional misconceptions. The proposed teaching strategies are basically in line with the classical propositions given by Fischbein for building secondary intuitions onto the partly problematic primary intuitions (1975):

"For instance, in order to create new correct probabilistic intuitions the learner must be actively involved in a process of performing chance experiments, of guessing outcomes and evaluating chances, of confronting individual and mass results a priori calculated predictions, etc. New correct and powerful probabilistic intuitions cannot be produced by merely practising probabilistic formulae." (Fischbein, 1982, p. 12) The common question for research and development of all these conceptions (with explicit connection to conceptual change or without) is the following:

How to initiate a sustainable development from prior individual conceptions to the intended mathematical conceptions?

Beyond the domain-specific answers given by Fischbein and others for probability, it proved of a valuable research strategy in other domains to investigate the learners' prior conceptions and put them into relation to a carefully specified catalogue of scientific conceptions to be learned. By contrasting individual and intended conceptions, one can gain ideas for the development of fruitful learning environments that facilitate the conceptual change process (this is, in short terms, one basic idea of the research program of Educational Reconstruction which is presented in Section 3).

\section{Suggesting a Complementary Horizontal View}

As long as the focus of research and development is on the vertical transformation from prior conceptions to mathematical conceptions, this refers to a learning theory which is based on a vertical view.

Vertical views are characterized by the aim of overcoming individual (mis-)concepttions and carefully substituting them by regular conceptions, like the primary intuitions (Fischbein, 1975 ) that are to be transformed into secondary ones. 
Without any doubt, this vertical view is very important for the conceptions of probability. Nevertheless, it shall here be complemented by a horizontal view. The horizontal view starts from the empirical observation that the far reaching aim of conceptual change, i.e. of overcoming individual (mis-)conceptions by mathematics classrooms is often not reached. Many empirical studies show that individual conceptions often continue to exist next to the new conceptions and that they are activated situatively (cf. Duit \& Treagust, 2003). Shaughnessy (1992) and Konold (1989) have emphasized this observation for probability: when people make decisions in probabilistic situations, both the collection of informal prior strategies as well as taught probabilistic strategies are presumably available. Konold emphasizes that "which of these is applied in a particular instance is a function not only of individual differences in knowledge of probability but also of situation variables." (Konold, 1989, p. 61)

Petri and Niedderer (2001) have explained this phenomenon for the domain of physics and described it in their theoretical model of cognitive layers. They emphasize that "students can activate opposed explaining strategies or conceptions for a given problem without any need for a strong variation of context" (Petri \& Niedderer, 2001, p. 53, translation SP).

The theoretical construct of a cognitive layer system allows them to assign individual explaining strategies and conceptions to layers which are developed at different moments in the learning biography and can build upon each other structurally. Exploratory case studies show how these layers co-exist, that is why they are here conceptualized as being stratified horizontally, not vertically. They show how they can differ with respect to the relative strength of the scientifically intended conceptions.

The model of cognitive layers can help to understand the vignette of Anne in the introduction: Some weeks before she asked her question "Do you want me to do it with probability or with my normal thinking?", Anne had successfully acquired Laplace's probability concept in different tasks and had applied it in different tasks. But when asked some weeks later to bet in a new dice game (on the most likely sum of two dices), she posed this quoted question. Anne seemed to be aware of the co-existences of two different cognitive layers. She knows that usually, mathematics teachers value other layers than her "normal thinking". At the same time, the expression "my normal thinking" expresses that she could not really become acquainted with the intended mathematical conceptions so far. She does not yet consider this cognitive layer to be her thinking which gives evidence of a relative weakness of this new cognitive layer.

In the concrete moment, Anne is not sure when to activate the new layer and hopes that the teacher "allows" her to go back to the more familiar "normal thinking". The beginning of the 
question "do you want me to" gives evidence that Anne would have directly chosen her "normal thinking" if the moment would have been out-of mathematics classroom and without her teacher being present.

This story of Anne tells only a singular but nevertheless compelling case, and it is completely in line with the results from Petri \& Niedderer's (2001) systematic empirical studies. Both suggest the evolution of a hypothetical answer to the question why some people do not activate even elementary stochastic conceptions in out-of-school contexts. This hypotheses shall be pursued in Section 4.1.

The descriptive empirical findings concerning a horizontal view for conceptual change have also impacts on the normative dimension: Is it really an adequate aim to demand a complete transformation of conceptions? For many science education researchers, the aim of a conceptual change process is not the complete substitution of prior conceptions by scientific ones, but the shift of contexts in which everyday and scientific conceptions are to be activated (Duit \& von Rhöneck, 1996, p. 146).

“Conceptual change does not imply that initial conceptions are ,extinguished'. Initial conceptions, especially those that hold explanatory power in non-scientific contexts, may be held currently with new conceptions. Successful students learn to utilize different conceptions in appropriate contexts.” (Tyson et al., 1997, p. 402)

In Prediger (2004), this perspective was characterized as a horizontal view, and it was discussed carefully by relying on the theory of intercultural learning. Here, the focus for the horizontal view is on the idea that learning processes should be conceptualized on the basis of a persisting co-existence of prior and mathematical conceptions. This idea is in line with Abrahamson and Wilensky's (2007) approach to take primary intuitions as legitimate ideas which can persist when weaved into a new framework. For this, the students' repertoires of conceptions and strategies have to be extended.

Hence, the research question concerning the formation of conceptions must be refined in an vertical view into he following:

(4) How can the individual repertoire of prior conceptions be extended to mathematical conceptions, and how can learners be enabled to chose the adequate conceptions in varying contexts?

It is clear that this question can only be answered by careful empirical studies which clarify the differences and commonalities as asked in the third question: 
(3) What are the main similarities and main differences between everyday and mathematical conceptions for the specific subject probability that feed the perception of a gap?

Before presenting some selected results from suitable case studies in Section 4, the next section will provide an answer to the methodological question:

(6) In which research framework can the empirical studies concerning question (3) be combined most successfully with design considerations of question (5)?

In the following section, the research program of Educational Reconstruction is presented since it allows to follow the vertical and horizontal descriptive and constructive questions by integrating different approaches of didactical research and development.

\section{THE EDUCATIONAL RECONSTRUCTION PROGRAM}

The Educational Reconstruction Program was originally developed in science education as a theoretically based framework for subject related research and development in teaching and learning (Duit, Gropengießer, \& Kattmann, 2005). The program shares its orientation of mathematics and science education as a design science (Wittmann, 1995) with many researchers who emphasize that design experiments with long-term iterative processes of design and theory development are a major task for the discipline of mathematics education (e.g. Cobb et al. 2003).

The Educational Reconstruction Program has a special focus for its design activities, namely the mediation between individual and scholarly conceptions. On the basis of the sketched learning theory, the declared aim is to facilitate conceptual change processes in vertical and horizontal view by specifying links between learners' conceptions and scientific conceptions and building upon these links for the design of learning environments.

For this aim, three central tasks of mathematics and science education are carried out (see Figure 1):

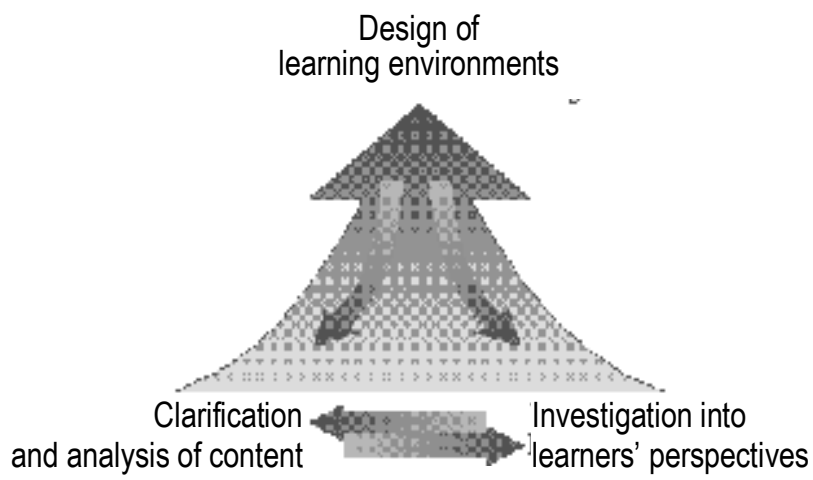

Figure 1: Integrating three components of (Science and) Mathematics Education in the Educational Reconstruction Program 
- firstly, the clarification and analysis of subject matter (like probability);

- secondly, the investigation into learners' perspectives with a focus on conceptions about the chosen mathematical or scientific subject;

- thirdly, the design of learning environments (e.g. instructional materials, learning activities, lessons or learning sequences).

The component of clarification and analysis of content is based upon the assumption that the content of school mathematics is not completely determined by the academic discipline. Instead it has to be reconstructed according to specific educational intentions with respect to contexts, genesis and meaning. This clarification is influenced by two other components:

"Clarification and analysis of science content is informed by the other two components of Educational Reconstruction. The emerging design of a learning environment and its content requirements will narrow down the extent to which the particular science content has to be clarified. Our awareness of the students' point of view may substantially influence the interpretation of a particular science content so that a different position does not only improve the researchers' understanding of learning but also of the referring science content" (Duit et al., 2005)

Methodologically, this clarification can, for example, be guided by Didactical Phenomenology according to Freudenthal (1983) and by Educational Analysis according to Klafki (1995, see Duit et al., 2005 for more details).

The component of investigation into learners' perspectives is crucial for the constructivist research program for being able to include the learners' starting points into the development of learning trajectories. Methodologically, this component demands empirical research on individual conceptions and their backgrounds which is usually done by case studies in clinical interviews or classroom observations.

These different aspects are consequently integrated for the third component, namely the design of learning environments which mediate horizontally and vertically between the learners' perspectives and the mathematical issues to be constructed.

Each of these three components of the program has insularly been addressed in many studies in mathematics and science education and with many different interesting methodologies. The main incentive of the Educational Reconstruction Program is their integration within one longer-term project by building upon the different results in an iterative process of research and development within a theoretically guided program. 
Within this iterative process, the key step is the careful confrontation of mathematical and individual perspectives since this step has deep impacts on the understanding of both parts. This mutual effect can be conceptualized by a motto given in a quotation of Freudenthal (cf. Prediger, 2005): "I want to observe learning processes in order to understand mathematics better." (Freudenthal, 1974, p. 124)

With this motto, the usual relation between educational analysis and empirical research on learning processes is inversed in a way which is astonishing at first sight. Freudenthal (e.g., 1983) and others have often shown that a careful a priori analysis of contents is necessary in order to understand learning difficulties. The quoted statement refers to the inverse direction which is less usual but equally important: the careful analysis of learning processes and especially appearing obstacles can contribute fundamentally to an epistemologically careful analysis of the mathematical content.

\section{FIRST STEPS IN AN EDUCATIONAL RECONSTRUCTION OF PROBABILITY}

Having laid some conceptual and theoretical foundations in Section 2 and 3, this section documents the first steps of this research process that takes place within the Educational Reconstruction Program. These first steps here serve as a methodological case study to introduce the research program, and this is why the section does not follow the usual structure of presenting research results. Instead, the iterative research process and the emergence of scientific insights into the field are presented in the order of their genesis, without strong emphasis on the procedures of data analysis because this would distract from the longer-term perspective.

\section{Results from a Preliminary Study as Contrasting Example}

In order to analyse the transition problem and its possible reasons (research questions (2) and (3)), a preliminary study was conducted as a classroom observation in a grammar school class (grade 10) during the students' first encounter with probability. From this study, only some results can be presented here (see Prediger, 2005 for more details).

In the second lesson of the teaching unit, the students played the game "Sum of Two Dice". In small groups they were supposed to bet on the number which is most likely to appear as a sum of two dice. The students' journals and their video-taped interaction gave some impression how they approached the situation in a probability class. 
Although differences could be reconstructed in the class (e.g. the use of representations, the choice of event space, and the interplay between the empirical and theoretical perspectives of the problem situation), there was one striking uniform phenomenon: There was no single student in the classroom who did not try to determine the probability of each sum, either by theoretical considerations like counting the possibilities for the sums in an event space (Laplace probability) or empirically by specifying the relative frequency of the sums in (more or less long term) experiments. Both activities can be called probabilistic approaches even if they were not always perfect in their concrete implementation (e.g. often, the event space was not correctly chosen or the experiments to short, e.g. for $n=50$ ).

This result is contrasting to those of many studies showing that people refuse to activate probabilistic conceptions in analogue situations out of school (Shaughnessy, 1992). The class seemed to be completely prepared to adopt probabilistic approaches after only 45 minutes of instruction in probability. Whereas many people out of school argue that one cannot determine the best bet by probability at all, the students in the observed classroom had no doubt at all about the sense of using either theoretical or empirical probabilistic conceptions.

In searching for first reasons for the ineffectiveness of probability teaching, this result was a first instance for the context-dependency of cognitive layers (see section 2). Do probabilistic conceptions only make sense in classroom contexts but not outside?

Furthermore, this preliminary study gave first evidence for the impact of the implicit didactic contract between teacher and students (Brousseau, 1997). The students in this classroom perfectly knew that in a teaching unit on probability, they are expected to use probabilistic conceptions for their bets in the game of two dice. (One student stated it explicitly: "I knew it's probability, because this is what we learned in the last lesson").

But once the didactic contract is out of work, the seemingly constructed knowledge appears to become unstable, and the gap becomes to big to be overcome.

\section{Investigations into Learners' Perspectives - A short report on an interview study} Research design

In order to investigate into learners' perspectives more independently from mathematics classrooms, a clinical interview study was conducted with 10 dyads of children who had not encountered probability in school before. In order to enhance explicit communication, the 20 
children (at the age of 10 or 11) were interviewed in pairs for about $45 \mathrm{~min}$. All interviews were completely videotaped.

The interviews were guided as clinical game interviews (Wollring, 1994) and based on the slightly modified game "Sum of Two Dice": The children were supposed to bet on number cards between 1 and 12. The winning number was determined by the sum of two thrown dice. Childrens' activities during the game interview were betting, playing, journalizing the throwing outcomes, and reflecting on the question "Which is the smartest number to bet on?".

In this setting, the research question (3) was followed by reconstructing students' preinstructional conceptions and strategies. This was operationalized by analyzing how children explain and justify the dice results and their decisions for betting in the game situation independent of mathematics classrooms. Hence, the research interest was not focused on the childrens' interpretations of existing conventional mathematical concepts (as it is often the case in empirical studies), but on their individual conceptions of moments in the game situations. The classical probabilistic concepts can emerge in order to conceptualize the situation, but they do not necessarily emerge for all children.

\section{Data analysis}

The transcripts of all interviews were analysed sequentially in a first step and coded closely to the text in a second step in a category-developing way (Flick, 1999) by the author and another well-trained coder. The resulting coding scheme covered seven categories for individual conceptualizations of the way in which the children explained or justified the moments of the game.

The built categories were (by theoretical considerations) assigned to different cognitive layers which are not hierarchically organised. Here, the central categories for individual conceptions are presented each with a typical statement taken from the transcripts:

\section{Cognitive Layer: Everyday conceptions}

- significance conception: sums are chosen or the throwing is explained due to the individual significance of the number (e.g. "I have thrown the 8 several times. And I already know why. [...] Because I am born on 16/8.”) 
- reachability conception: single numbers and some sums are considered to be different likely to appear, hence sums differ in their reachability with respect to their summands (e.g. "For 6, you can get Five and One, but this is difficult [...] if you are really lucky, you get two Threes.”)

- persuasibility conception: dice can be persuaded or influenced to throw a wished sum. (e.g. "Sometimes, I thought, oh dear, I urgently need a 6, and then I had a 6.")

\section{Cognitive Layer: Empirical conceptions}

- long-term empirical "experiences": some students refer to long term experiences to estimate the likelihood of sums: "When playing games I have always been lucky with the 5."

- empirical experiences in the game interview: decisions are taken with reference to former outcomes in the game ("I will take the 10, because we saw that the dice can do it.")

\section{Cognitive Layer: Theoretical conceptions}

- random is arbitrary: refuse to explain anything since random is considered to be not determinable at all ("We cannot say anything, it is just luck.")

- Laplace conception: counting possibilities of outcomes as a theoretical strategy to specify the probability ("I have chosen the 7, because there are six ways to get it, and for the others, there are only five or three. Hence, we can more easily throw a 7.")

For controlling the reliability of the coding scheme, a third, independent coder reanalysed the data and achieved an interrater agreement of Cohen's kappa $=0.75$ for assigning the categories and $=0.96$ for assigning the layers.

At first sight, these layers seem to correspond to the different approaches to probability as discussed by many authors: the subjective approach, the empirical (frequentistic) approach and the classical, objective approach (e.g. Kapadia, 1988). But considered more deeply, this parallelizing would be misleading. The everyday conceptions here do not correspond to the subjective approach, in which probability is treated as the degree of belief (e.g. Kapadia, 1988). This is especially true for the persuability conception, a well known everyday conception which has often been found in empirical studies (e.g. Fischbein et al., 1991; Wollring, 1994). They appear as alternative cognitive layers even in the thinking of well educated adults. Also the significance conception is well documented in the literature (e.g. Wollring, 1994; Borovcnik \& Peard, 1996), it might be a candidate for transforming into a subjective probability conception in a later learning process. Underneath the reachability conception, one can often find the well known refusal of children to ascribe equal probability to each elementary outcome (e.g. Green, 
1983). Even clearer, the expressed conceptions categorized in the empirical layer do not correspond directly to the intended frequentistic conception. The expressed idiosyncratic longterm experimental experience might sometimes be linked to the availability heuristic (Tversky \& Kahneman, 1973), the empirical evidence in the game interview might be a point of contact for a later transformation into the intended conception. The conception "Random is arbitrary" is a theoretical position that does not connect to classical approaches either.

After coding and categorizing, the coded (and for this purpose decontextualized) statements were re-situated in the course of the transcript. This step of data analysis is important for reconstructing the individual reasons and senses behind the statements. Since the activation of different cognitive layers is considered to depend on the situation in which individuals have to take decisions (see Section 2.3), re-situating allows to reconstruct the moments in which the different individual conceptions appeared. Although all of them were formulated in the same global game situation, these moments (i.e. the micro-situations) differ enormously.

\section{Selected Result 1: Oszillation}

Already the categories in the coding scheme offer an important result of the first step of the data analysis. Once established, the coding scheme allowed an overview on the complete interviews and their development.

The main result of this overview is the reconstructed oszillation between different layers and conceptions. It is typical that all but two quotations by which the categories were illustrated come from one single pair of children (well shared between both of them). Most of the observed children used very different conceptions for explaining the concrete outcomes, the long-term patterns and their predictions. In only one out of 10 interviews, the two children experienced a linear learning process from the everyday layer to the mathematically more fruitful theoretical layer with a Laplace conception. In contrast, all other interviews show children who oscillate between different layers and conceptions forward and backward. Hence, the concurrence of cognitive layers even appears within the temporarily limited game interview situation.

\section{Selected Result 2: Patterns in micro-situated use}

For some categories, patterns could be reconstructed in which kind of micro-situations they were used. For example, the significance conception appeared most often in moments were the students tried to explain or predict single outcomes. 


\section{Discussion: Levels of development or situated layers?}

Before discussing the selected results, one important limit of the study must be mentioned: Given that only 10 pairs of children took part in the game interviews, there is already a wide spectrum of individual conceptions. Nevertheless, the data sample cannot be assumed to be saturated, one would have expected at least well known individual conceptions like the socalled equiprobability bias (Lecoutre, 1985) which had not yet appeared within the sample.

The result 1 concerning the oszillation between categories and layers is in definitive contrast to attempts of other researchers for specifying levels of developments in neo-piagetian traditions (e.g. Jones, Langrall, Thornton and Mogill, 1997). Whereas those researchers assign individual conceptions of probability, variance and expectation to certain levels of development which children reach at a certain age, the results here suggest that children (and also adults) move between different layers even within a sequence of approximately 45 minutes.

Many researchers in mathematics education concentrate their efforts on the elimination of these everyday conceptions and reach this aim with temporary but rarely sustainable success (Shaughnessy, 1992). In contrast to adopting this vertical view, this article revisits the wellknown empirical phenomenon in a horizontal view, in which the individual conceptions are not considered to be misconceptions that have to be overcome as soon as possible, but as concurrent conceptions which co-exist with newly developed mathematical conceptions even in the long run (see Section 2.3).

One explanation for the sustainability of these persisting (seemingly wrong) individual conceptions is that they might also have rational roots: individuals do not decide to abandon their everyday conceptions because they prove of value in certain situations. This is why Kattmann pleads for an analysis in a horizontal view in order to specify the reasons for the discrepancy.

"Beyond the formation and the stability of everyday conceptions, we often find reasons which determine the learning process themselves. That is why they cannot be simply excluded or overcome. Instead, knowing them allows to use the individual conceptions in a more adequate and effective way for the learning of subject matter content." (Kattmann,, 2003, p. 7, translation SP).

The reconstructed patterns in micro-situated use (Result 2) give an important access to make sense of students' thinking: If the activation of layers shows pattern in the micro-situated use, it might be more than an eliminable misconception. For explaining this point, the discussion 
is here focused on the example of one selected category, namely the significance conception (sums are chosen or throwing is explained due to the individual significance of the number).

As explained above, the significance conception is a well known individual approach which is an obvious misconception since "the dice do not know your birthday", as one interviewee said. Though, what can it mean to consider this individual conception to be a legitimate perspective? How to find any rational sense in it?

The step of re-situating the instances of the category shows that children are most likely to activate a significance conception in micro-situations where they focus their attention on the prediction or explanation of single outcomes instead of long-term patterns. This focus of attention on single outcomes has already been found in studies by Konold (1989) and Borovenik (1991) as an important factor for individual thinking:

"errors in reasoning under uncertainty arise not only from indiscriminate application of natural assessments, but also from analyses based on a different understanding of the goal in reasoning under uncertainty." (Konold, 1989, p. 61, italics added by SP].

Konold specified a model called the outcome approach: "According to this model, referred to as the outcome approach, the goal in dealing with uncertainty is to predict the outcome of a single trial. These same individuals tended to evaluate their predictions as being correct or incorrect after one trial. Furthermore, outcome-oriented participants often based predictions on a causal analysis of the situation. Numbers assigned as 'probabilities' were used occasionally to gauge the strength of these perceived causal factors." (Konold, 1989, p. 61)

Konold's hypotheses is supported by our study insofar as the importance of the outcome approach can be shown in many moments of the interviews, for example when children

- tried to explain the last outcome

- drew consequences from one outcome

- tried to predict the next outcome

- found evidence for the unpredictability of outcomes in one outcome which did not follow the theoretical considerations

- etc.

But unlike Konold's results, the analysis in this study could not affirm the outcome approach as a stable viewpoint of some children, but as appearing situatively: children sometimes adopted an outcome approach and sometimes didn't. They switched between the perspectives 
even without being aware of it. It depended on the special moment in the game interview, on the specific question of the interviewer or the specific aspect the children discussed with each other. The same children could adopt a long-term perspective two minutes later, e.g. when considering a tally sheet with 200 outcomes.

This observation of situatedness of activating an outcome-approach (being a background for the significance conception) is an important support for the horizontal view and the model of cognitive layers which coexist within single individuals.

\section{Confrontation of Mathematical and Individual Perspectives}

According to the Educational Reconstruction Program, the reconstruction of individual reasons can be strengthened methodologically by an explicit confrontation of mathematical and individual perspectives. This step of the research program is exemplified (see Figure 2) by the confrontation of only one individual conception with the intended mathematical conception.

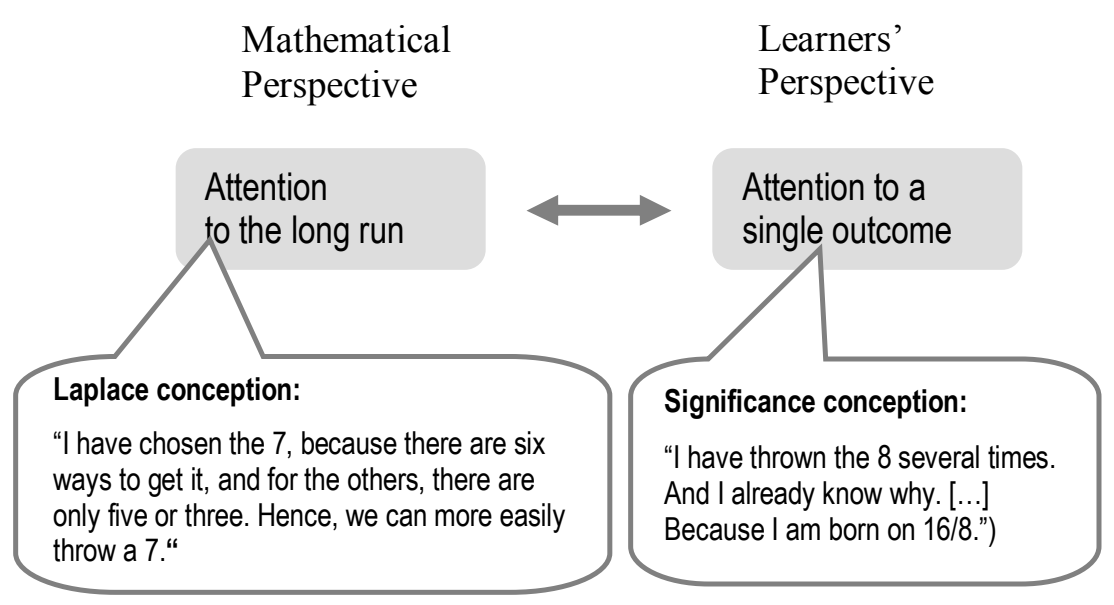

Figure 2: Diverging focus of attention as a source for discrepancies

For this, the selected category significance conception is now confronted with it's a mathematical counterpart by which the game situation could have mathematized successfully, the Laplace conception (possibilities of outcomes are counted as a theoretical strategy to specify the probability). Although the Laplace conception also appeared (rarely) as individual conceptions of interviewees, it is now treated as the representative of the mathematical perspective, whereas the significance conceptions is treated as one exemplary representative of the learners' perspective.

How does this help to make sense of the significance conception? Although the outcome approach was not a stable viewpoint, it was underlying nearly all moments when the significance 
perspective emerged. In order to make sense of the phenomenon, it is important to ask neutrally: What is an adequate strategy for explaining single outcomes? It turns out that the Laplace conception of counting possibilities is not more suitable for explaining single outcomes than the significance conception.

In the case of predicting single outcomes, the probability judgement must offer the most convincing measure of certitude for the individual (subjective probability, Kapadia, 1988). It can be supported by probability calculations according to the Laplace-rule. But applying this conception for predicting single outcomes is rarely secure, the prediction often fails with the result of deep disappointment. This serious limit leads many people to a significance conception which might offer alternative measures for certitude in which the individual can trust, with a higher subjective security.

Hence, whenever the outcome approach is underlying the interpretation of the microsituation, the significance conception is not much less adequate than approaches calculated by the Laplace rule.

The Laplace conception in its classical interpretation gains for secure predicting power only in the long-term perspective, not while focussing the attention on the single outcome. Whenever predictions or explanations for outcomes in the long run are given, the mathematical concepts prove to be superior to diverging subjective conceptions. .

Only those individuals who understand this important difference between short-term and long-term perspective and understand the limits of the mathematics concepts (as not being applicable securely to short-term considerations), can use probability in a judicious way, i.e. in game situations.

\section{Clarification of the Content}

Hence, one result of the confrontation of mathematical and individual perspectives, is the important characteristic of random which turned out to be a crucial point for the clarification of content:

"Random cannot be calculated for the single case. In the long run, it has a regularity. It is the main task for an introduction to probability to explicate this phenomenon." (HefendehlHebeker, 2003, p. 13, translation SP)

In a similar way, David Moore puts the phenomenon random into the centre of his introduction to probability and turns this characteristic into a definition for random: 
"Phenomena having uncertain individual outcomes but a regular pattern of outcomes in many repetitions are called random. 'Random' is not a synonym for 'haphazard' but a description of a kind of order different from deterministic one that is popularly associated with science and mathematics. Probability is the branch of mathematics that describes randomness." (Moore, 1990, p. 97)

The background of this characterization is the empirical law of large numbers. Although principally well-known, it gains a new meaning in this reconstructive context. The empirical law of large numbers explains why one can adopt probabilistic conceptions in a successful way although random cannot be calculated for single outcomes. It explains the sense and the preconditions, but also the limits of probabilistic considerations.

In the individual research process of the author, becoming aware of this role was an instance of Freudenthal's motto which conceptualizes the observation of learning processes as a source of better understanding mathematics itself. In the Educational Reconstruction Program, this is institutionalized by the step of investigation into learners' perspectives and its impact on the clarification of content. Hence, this offers a starting point for the reconstruction of elementary probability (see below).

Coming back to the law of large numbers, we can also understand the impacts of the horizontal view adopted in this paper in contrast to classical research approaches which focus on the identification of misconceptions: Tversky \& Kahneman (1971) introduced the term "law of small numbers" for the individual assumption that an a priori probability (e.g. specified by the Laplace rule) should also predict securely the relative frequency in experiments with small numbers of outcomes. This assumption has often been reapproved as a typical "misconception" (e.g. Borovcnik, 1991; Konold, 1989).

In contrast, in the horizontal view, this immediate result of an outcome approach is first considered to be a legitimate perspective which should be respected alongside the mathematical perspectives. "Wouldn't it be nicer, if it was true?", said one of the author's students in a discussion. This offers the opportunity to become aware of a major restriction of probabilistic conceptions: it would of course be more powerful to have also a law of small numbers, but stochastics is not able to guarantee this "better law". Hence, the phenomenon that many people believe in the law of small numbers does not only hint to individual deficits, but to a deficit of mathematics. From the individual's perspective, it is a legitimate and senseful request to look for secure predictions also for single outcomes. (Remark that accepting learners' question as legitimate is something different than a teacher or researchers who ask a student to predict a 
single outcome!) Hence, the often intuitively formulated "law of small numbers" might be a very interesting starting point for a fruitful reflection on stochastics not being able to fulfil this request since only the weaker law of large numbers applies to random phenomena.

In this way, the horizontal view offers a completely different conceptualization of the relation between individual and mathematical perspectives than it is usually implicitly proposed in mathematic education research.

Furthermore, it offers an answer to research question (4): How can the individual repertoire of prior conceptions be extended to mathematical conceptions, and how can learners be enabled to chose the adequate conceptions in varying contexts?

The analysis in a horizontal view shows that this aim can only be reached if the necessary divergence in perspective is made explicit, together with the connected divergence in the focus of attention, on the single outcome on the one hand and the long run on the other hand. For enabling learners to switch between the mathematical and the everyday perspective and to activate the mutual appropriate cognitive layer according to the specific micro-situation, they must attain an explicit awareness exactly of this divergence in focus of attention. The most important reason for this is that this awareness is an important precondition of an explicit and rational choice between the different available cognitive layers.

Hence, we claim to have a new learning content which is well described by HefendehlHebekers sentence "Random cannot be calculated for the single case. On the long run, it has a regularity." (see below). On the one hand, this seems self-evident, on the other hand, the analysis of (at least german) textbooks showed that it is not really discussed in most textbooks so far.

\section{First Ideas for the Design of Learning Environments: Making the Change of Perspective Explicit}

In the last section of his article, Konold makes suggestions for instruction which aim at overcoming the outcome approach by an intensive, scientist-like inquiry whether the outcome approach is really consistent with the beliefs of others, with the own beliefs and specially with empirical observations (Konold, 1989, pp. 152ff). Hence, his suggestions are similar to Fischbein's (1975), although without explicit reference to this source.

Konold's suggestions are convincing as far as a vertical perspective is adopted that aims at changing the students' initial conceptions in favour of the more fruitful focus of attention to the long-term experiments. This is also supported by Shaughnessy (1992): 


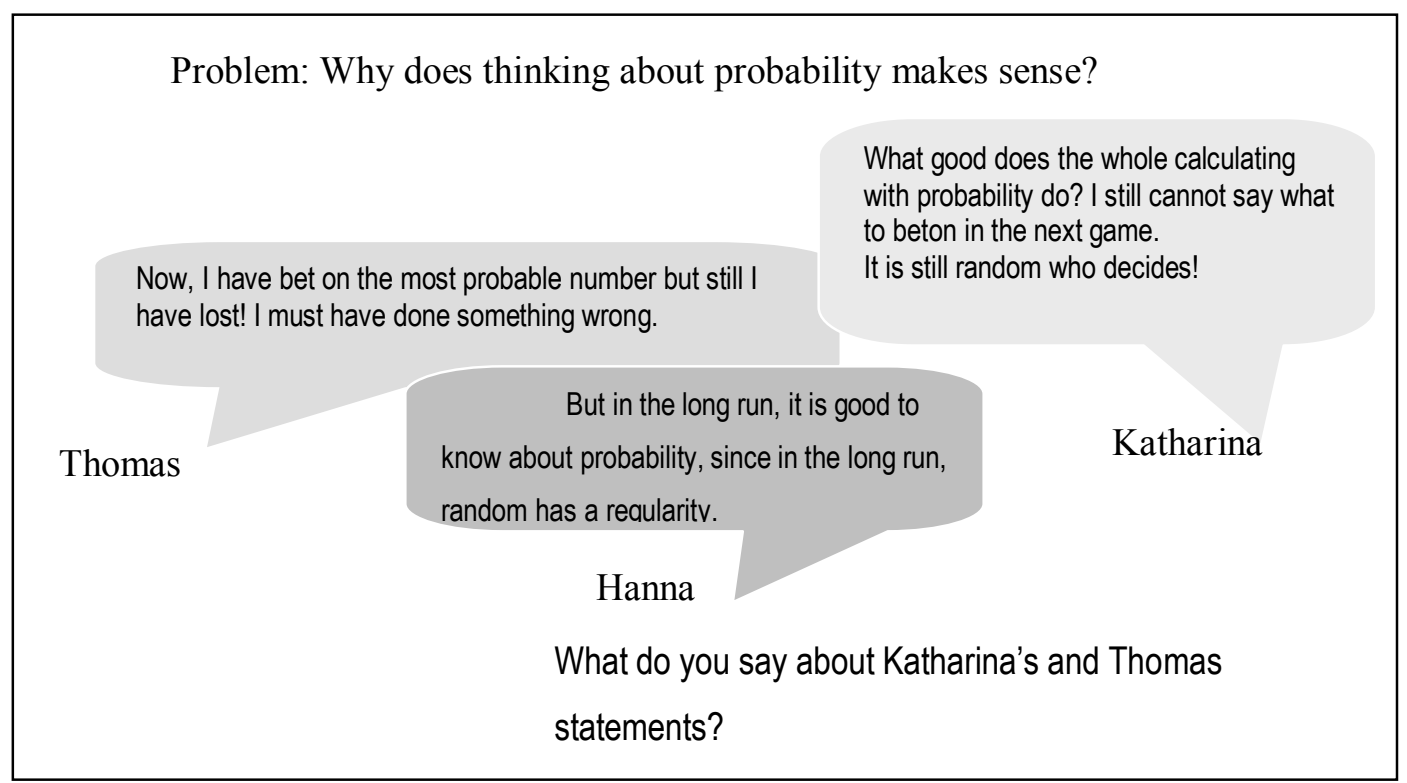

Figure 3: Problem for becoming aware of the necessary change of perspective

"It is important for us to begin our instructions by confronting both our students' deterministically entrenched paradigms, and their statistically naïve heuristics. We must create some dissonance within our students' past belief systems if we are to have a chance of replacing them with mathematical models. [...] Even this is no guarantee, though, as research has shown our students' stochastic tenets to be amazingly robust." (Shaughnessy, 1992, p. 486)

But it is exactly Shaughnessy's last phrase with the hint of the robustness of students' conceptions that again supports adopting a complementary, horizontal view. In a horizontal view, instruction should not aim at replacing the attention on the single outcome by long-term considerations, but at enhancing awareness that both are two different perspectives with different advantages and disadvantages which should be adopted in different situations.

This is crucial since one cannot easily say that the outcome-approach is false (as Konold, 1989 already emphasizes). In contrast it comprises the legitimate question how to predict the single outcome. Teachers should take the learners' disappointment very serious that probability has no secure answer to this important question.

In order to reach this awareness, the law of large numbers must be an important issue in the learning environment to be designed. Although there already exist several interesting suggestions for the law of large numbers in middle schools (e.g. Aspinwall \& Tarr, 2001), non of these make the role of the law of large numbers explicit as the main condition for applying probabilistic conceptions. 
Students do not learn this by theory alone, as the answers to the Problem in Figure 3 shows. The problem is also printed as a first proposition for an implementation of the intended aims. In this example, the different perspectives are concretized for the children as positions of different children. In this way, students can communicate without entering an abstract meta-level.

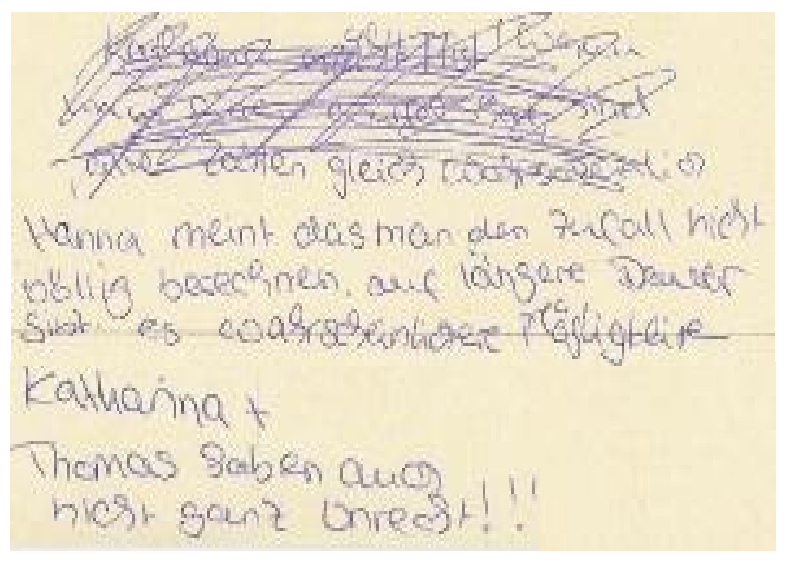

Katharina tells rubbish. When you throw a dice, all numbers are equally probable.

Hanna means that you cannot completely calculate random. In the long run, there are more probable possibilities.

Katharina + Thomas are also not completely wrong!!!

The problem was posed at the end of a classical three-week-unit on probability and random in a grade 7 comprehensive school. The results show that it is not self-evident to be aware of the divergence of perspectives. Only five out of 17 students agreed to Hanna and were able to adopt a long-term perspective in this case, as the following answer: "Hanna means that probabilities are approximately fulfilled when you have longer experiments."

Also five children agreed to Thomas who stated that probability considerations cannot help since random is hazardous: "I mean that you can really not calculate which number will appear since random is untamable."

Over all, these results give hints that the change in perspective is not made by many children even after three weeks of probability in classroom, and only some are aware of the divergence in perspectives.

Lisa's answer in Figure 4 shows that these kind of tasks might be a fruitful format to reflect on the issue. Lisa has written her text in three steps. First, she answered like many of her colleagues and agreed to the short-term perspective. But while working on the problem, she modified her perspective, crossed her first answer and agreed to Hanna. In the third step, she added the last phrase which expressed a first awareness of the inconsistency of the phenomenon and acknowledged that also Katharina and Thomas have legitimate perspectives. Lisa' process 
(although far from being perfect), is a first example of how the process of becoming aware of the divergent perspectives might take place.

This process can be facilitated by problems like the one in Figure 3 which explicitly initiate the reflection on different perspectives (Buechter, Leuders, Hußmann, \& Prediger, 2005 for more suggestions for the design of suitable learning environments).

\section{Outlook on Further Developments and Research}

The author's research group in Dortmund is currently developing a learning environment for low achieving students in grade 6 which puts the experimental experience with the law of large numbers and the reflection on its meaning into the centre (Hußmann \& Prediger 2009, Prediger \& Rolka, 2008). In this learning environment the different perspectives are implemented as concurrent betting strategies in a game which was explicitly designed for this purpose. The learning environment is characterized by a high degree of reflective tasks. This is born from the conviction of the developers that only the explicit reflection can enable students to chose rationally between different available cognitive layers and that this might hopefully increase the sustainability of the constructed probabilistic conceptions. Also newer developments like Abrahamson \& Wilensky (2007) give hope that the problem can be treated constructively in the future.

\section{CONCLUSION}

"Do you want me to do it with probability or with my normal thinking?" As long as Anne and many other students and adults experience this gap between their everyday thinking and the mathematical thinking without opportunity to reflect on differences and conditions when to use which cognitive layer, probability classrooms will always risk to fail in their important elementary aim to anchor the concept of probability in the individual thinking in such a way that people activate probabilistic conceptions in suitable random situations out of school.

The article gave accounts for this limited success by analysing the phenomenon in terms of the conceptual change approach and the horizontal view on the construction of conceptions.

The deeper analysis and search for reasons resulted in the insight that the different perspectives have their roots in diverging foci of attention, the mathematically suitable long-term perspective being in concurrence to the more natural short-term attention to single outcomes. The codification and categorization of the interviews showed that many students do not adopt one 
stable perspective but oszillate between the concurrent perspectives even without being aware of it.

These analyses offer starting points for the development of learning environments that can built successful bridges between individual and mathematical conceptions. Adequate learning environments must

- make explicit different individual conceptions and strategies

- give the opportunity of intense experiments for questioning the prior conceptions

- offer opportunities to become aware of the underlying differences between short-term and long-term perspectives and their typical questions, benefits and limits.

In this way, the Educational Reconstruction Program offered the possibility to specify the roots of obstacles and to develop guidelines for designing learning environments which respect the horizontal view. The learner shall be enabled to chose adequate conceptions in varying mutual situations instead of aiming at overcoming the prior conceptions.

\section{REFERENCES}

Abrahamson, D. \& Wilensky, U. (2007). Learning axes and bridging tools in a technology-based design for statistics. International Journal of Computers for Mathematical Learning 12, 23-55.

Aspinwall, L. \& Tarr, J. E. (2001). Middle school students' understanding of the role sample size plays in experimental probability. Journal of Mathematical Behavior 20, 1-17.

Borovcnik, M. \& Peard, R. (1996). Probability. In: Bishop, A. J. et al. (eds.). International Handbook of Mathematics Education. Dordrecht: Kluwer, 239-288.

Borovenik, M. (1991). A complimentarity between intuition and mathematics. In: D. Vere-Jones (Ed.). Proceedings of the third international conference on teaching statistics, Vol. 1. Voorburg: International Statistical Institute, 363-369.

Brousseau, G. (1997). The theory of didactical situations in mathematics. Dordrecht: Kluwer.

Buechter, A. , Hußmann, S., Leuders, T., \& Prediger, S. (2005). Den Zufall im Griff? - Stochastische Vorstellungen fördern. Praxis der Mathematik in der Schule 47(4), 1-7.

Cobb, P., Confrey, J., diSessa, A., Lehrer, R., \& Schauble, L. (2003). Design experiments in educational research. Educational Researcher 32(1), 9-13.

Duit, R. \& Treagust, David F. (2003). Conceptual change: a powerful framework for improving science teaching and learning. International Journal of Science Education, 25(6), 671-688. 
Duit, R. \& von Rhöneck, C. (1996) (eds.). Lernen in den Naturwissenschaften. Kiel: Institut für Pädagogik der Naturwissenschaften an der Universität Kiel.

Duit, R., Gropengießer, H. , \& Kattmann, U. (2005). Towards science education research that is relevant for improving practice: the model of educational reconstruction. In: H. Fischer (ed.) Developing standards in research on science education. London: Taylor \& Francis, 1-9.

Ernest, P. (1994). Constructivism: which form provides the most adequate theory of mathematics learning?. Journal für Mathematikdidaktik 15 (3-4), 327-342.

Fischbein, E. (1975). The intuitive sources of probabilistic thinking in children. Reidel: Dordrecht.

Fischbein, E. (1982). Intuition and proof. For the Learning of Mathematics 3(2), 9-19.

Fischbein, E. et al. (1991). Factors affecting probabilistic judgements in children and adolescents. Educational Studies in Mathematics 22(6), 523-549.

Flick, U. (1999). Qualitative Forschung. Theorie, Methoden, Anwendung in Psychologie und Sozialwissenschaften. Frankfurt: Rowohlt Taschenbuch Verlag.

Freudenthal, H. (1974). Sinn und Bedeutung der Didaktik der Mathematik. Zentralblatt für Didaktik der Mathematik $8(6), 122-124$.

Freudenthal, H. (1983). Didactical Phenomenology of mathematical structures. Kluwer: Dordrecht.

Gerstenmaier, J. \& Mandl, H. (1995). Wissenserwerb unter konstruktivistischer Perspektive. Zeitschrift für Pädagogik $33,867-888$.

Green, D. R. (1983). School pupils probability concepts. Teaching Statistics 5(2), 34-42

Gropengießer, H. (2001). Didaktische Rekonstruktion des Sehens. Wissenschaftliche Theorien und die Sicht der Schüler in der Perspektive der Vermittlung. Oldenburg: Didaktisches Zentrum der Universität Oldenburg.

Hefendehl-Hebeker, L. (2003). Didaktik der Stochastik I: Wahrscheinlichkeitsrechnung. Manuscript, Universität Duisburg.

Hußmann, S. \& Prediger, S. (2009, in press). Je größer die Wurfzahl, desto sicherer die Wette - Wettkönig. To appear in Praxis der Mathematik 51(25). [The larger the number of throws, the more secure the bet - 'Betting King']

Jones, G., Langrall, C., Thornton, C. and Mogill, A. (1997). A framework for assessing and nuturing young children's thinking in probability. Educational Studies in Mathematics, 32, 101-125.

Kahneman, D. \& Tversky, A. (1982). On the study of statistical intuitions. Cognition 11, 123-141.

Kaldrimidou, M. \& Tzekaki, M. (2006). Theoretical issues of mathematics education: some consideration. In: M. Bosch (eds.). Proceedings of the 4th Congress of Research in Mathematics Education, Spain 2005, 12441253.

Kapadia, R. (1988). Didactical Phenomenology of Probability. In R. Davidson \& J. Swift (eds.). The Proceedings of the second International Conference on Teaching Statistics. Victoria, B.C.: University of Victoria.

Kattmann, U. \& Gropengießer, H. (1996). Modellierung der didaktischen Rekonstruktion. In: Duit \& von Rhöneck 1996, 180-204. 
Kattmann, U. (2003). Vorwort. In: H. Gropengießer. Lebenswelten - Denkwelten - Sprechwelten. Wie man Vorstellungen der Lerner verstehen kann. Oldenburg: Didaktisches Zentrum der Universität Oldenburg, 7-8.

Klafki, W. (1969 / 1995). On the problem of teaching and learning contents from the standpoint of critical-constructive Didaktik. In S. Hopman, \& K.Riquarts, (eds.)., Didaktik and/or Curriculum. Kiel, Germany: Leibniz-Institute for Science Education (IPN), 187-200. (originally 1969)

Knuth, R.A., \& Cunningham, D. J. (1993). Tools for Constructivism. In T.M. Duffy, J. Lowyck, \& D.H. Jonassen (eds.). Designing Environments for Constructive Learning. Berlin: Springer, 163-188.

Konold, C. (1989). Informal Conceptions on Probability. Cognition and Instruction 6(1), 59-98.

Konold, C. (1991). Understanding students' beliefs about probability. In: E. von Glasersfeld (ed.). Radical Constructivism in Mathematics Education. Dordrecht: Kluwer, 139-156.

Lecoutre, M. P. (1985). Effect d'informations de nature combinatoire et de nature fréquentielle sur les judgements probabilistes. Recherches en Didactique des Mathématiques, 6, 193- 213.

Moore, D. S. (1990). Uncertainty. In: Steen, L. A. (ed.). On the shoulders of giants: New approaches to numeracy. Washington: National Academy press, 95-137.

Petri, J. \& Niedderer, H. (2001). Kognitive Schichtenstrukturen nach einer UE Atomphysik (SII). Zeitschrift für Didaktik der Naturwissenschaften 7, 53-68.

Posner, G. et al. (1982). Accommodation of a scientific conception: Toward a theory of conceptual change. Science Education 66(2), 211-227.

Prediger, S. \& Rolka, K. (2008). Betting as a pathway to the law of large numbers - Self-construction of strategies for initiating conceptual change. To appear in: M. Borovcnik \& D. Pratt (eds.). Proceedings of ICME 11 Topic Study Group 13: Research and development in the teaching and learning of probability, Mexico 2008.

Prediger, S. (2004). Intercultural Perspectives on Mathematics Learning - Developing a Theoretical Framework. International Journal of Science and Mathematics Education 2 (3), 377-406.

Prediger, S. (2005). „Auch will ich Lernprozesse beobachten, um besser Mathematik zu verstehen.“ Didaktische Rekonstruktion als mathematikdidaktischer Forschungsansatz zur Restrukturierung von Mathematik. Mathematica Didactica 28 (2), 23-47.

Prediger, S. (2008). The relevance of didactic categories for analysing obstacles in conceptual change: Revisiting the case of multiplication of fractions. Learning and Instruction, 18 (1), 3-17.

Shaugnessy, J. M. (1992). Research in probability and statistics: reflections and directions. In: D. A. Grouws (ed.). Handbook of Research on Mathematics Teaching and Learning. Macmillan: New York, 465-494.

Sierpinska, A. \& Lerman, S. (1996). Epistemologies of Mathematics and of Mathematics Education. In: Bishop, A. J. et al. (eds.). International Handbook of Mathematics Education. Dordrecht: Kluwer, 827-876.

Tversky, A. \& Kahneman, D. (1971). Belief in the law of small numbers. Psychological Bulletin, 76, 105-110.

Tversky, A., Kahneman, D. (1973). Availability: a heuristic for judging frequency and probability. Cognitive Psychology 5, 207-32. 
Tyson, L.M., Venville, G.J., Harrison, A.G., \& Treagust, D.F. (1997). A multi-dimensional framework for interpreting conceptual change in the classroom. Science Education 81(4), 387-404.

Vosniadou, S. \& Verschaffel, L. (2004) (eds.). The Conceptual Change Approach to Mathematics Learning and Teaching. Learning and instruction 14(5), 445-548.

Watson, J. (2005). Variation and Expectation as Foundations for the Chance and Data Curriculum. In Clarkson, P., Downton, A, Gronn, D. \& Horne, M. (eds.). Building Connections: Theory, Research and Practice: Proceedings of the Twenty-eighth conference of the Mathematics Education Research Group of Australasia, Vol. 1, 35-42.

Wittmann, E. C. (1995). Mathematics education as a 'design science'. Educational Studies in Mathematics 29(4), 355374.

Wollring, B. (1994). Qualitative empirische Untersuchungen zum Wahrscheinlichkeitsverständnis bei Vor- und Grundschulkindern. Habilitation Thesis, Universität Münster.

\author{
Author : Susanne Prediger \\ E-mail : prediger@math.tu-dortmund.de \\ Address : : TU Dortmund \\ Institute for Development and Research in Mathematics Education \\ Vogelpothsweg 87 \\ D.44227 Dortmund, Germany
}

